\title{
Study of microRNA expression profiling as biomarkers for colorectal cancer patients in Lebanon
}

\author{
SOUMAIAH ABOU STAITEIEH ${ }^{1}$, LAILA AKIL ${ }^{2}$, RAWAN AL KHANSA ${ }^{1}$, RIHAB NASR $^{3}$, \\ ZAINAB AL SAGHEER ${ }^{4}$, BILAL HOUSHAYMI ${ }^{1}$ and RAGHIDA ABOU MERHI ${ }^{1}$ \\ ${ }^{1}$ Genomics and Surveillance Biotherapy Laboratory, Biology Department, Faculty of Sciences, \\ R. Hariri Campus, Lebanese University, Hadath $1003 ;{ }^{2}$ Anatomy and Pathology Department, Bahman Hospital, \\ Haret Hreik, Mount Lebanon 128-25; ${ }^{3}$ Department of Anatomy, Cell Biology, and Physiological Sciences, \\ American University of Beirut, Beirut 1107-2020; ${ }^{4}$ Applied Mathematics Department, \\ Faculty of Sciences, R. Hariri Campus, Lebanese University, Hadath 1003, Lebanon
}

Received May 17, 2021; Accepted September 15, 2021

DOI: $10.3892 / \mathrm{mco} .2021 .2473$

\begin{abstract}
The high incidence and mortality rates of colorectal cancer (CRC) reveal its hazardous effect globally. Thus, it is important to diagnose CRC at an early stage to decrease its burden and improve survival rates. Previous studies have investigated the role of short non-coding microRNAs (miRNAs or miRs) in numerous types of cancer, including CRC. Previous studies have been performed to investigate the role of miRNAs as biomarkers in diagnosis, prognosis and prediction of CRC development. The aim of the present retrospective study was to identify the expression levels of miR-31, miR-145, miR-146b and miR-186 to highlight their role in CRC diagnosis and progression at different stages of the disease (precancerous polyp, adenoma and adenocarcinoma) in a Lebanese population. The expression levels of miRNAs was revealed using TaqMan reverse transcription-quantitative PCR on formalin-fixed paraffin-embedded tissues from Lebanese patients at different stages; their diagnostic value was determined using a receiver operating characteristics curve. Compared with healthy controls, miR-31 was upregulated $(\mathrm{P}<0.0001)$ at all stages. By contrast, miR-145, miR-186, and miR-146b were significantly downregulated at all stages ( $\mathrm{P}<0.0001, \mathrm{P}=0.0009$ and $\mathrm{P}=0.0241$, respectively). Of the four miRNAs studied, miR-31 and miR-145 were identified as potentially useful diagnostic factors, with an area under the curve of 0.7771 and 0.8269 and diagnostic accuracy of 71.3 and $78.5 \%$, respectively. These data suggested that miR-31 and miR-145, upon further clinical validation, may be used as
\end{abstract}

Correspondence to: Dr Raghida Abou Merhi, Genomics and Surveillance Biotherapy Laboratory, Biology Department, Faculty of Sciences, R. Hariri Campus, Lebanese University, Hadath 1003, Lebanon

E-mail: raboumerhi@ul.edu.lb

Key words: colorectal cancer, microRNA, biomarkers, diagnosis, Lebanese population potential diagnostic biomarkers for the early detection of CRC at the polyp stage.

\section{Introduction}

Worldwide, colorectal cancer (CRC) is considered one of the most common malignancies and a significant threat to health $(1,2)$. In 2020 , CRC was ranked the fourth most common type of cancer and the third most common cause of cancer deaths worldwide with an incidence rate of 24.8 and a mortality rate of 12 cases per 100,000 , according to the World Health Organization $(3,4)$. In Asia, the incidence rate is increasing, making CRC a notable health burden (5). In the Lebanese population, CRC ranked fourth among men for the most common types of cancer with an expected incidence rate of 17.5 cases per 100,000 and ranked second among women with an expected incidence rate of 10.6 cases per 100,000 in 2020, making it one of the highest reported types of cancer in the country (6).

CRC is initially characterized by polyps (Ps), which are classified according to their growth pattern as adenomatous or serrated. Ps progress to the adenoma (Ad) stage within 10-20 years, followed by invasive adenocarcinoma (ADC). Since there is a slow progression from the precancerous $\mathrm{P}$ to invasive ADC stage, early detection can decrease the mortality rate and increase the chances of recovery and survival $(7,8)$. A study demonstrated that early stage diagnosis in patients with CRC led to a decrease in the CRC mortality rate in Australia (9). Furthermore, in the United Kingdom, diagnosis at early stages has been shown to increase the survival rate compared with diagnosis at later stages (9).

A number of screening tools have been utilized for early detection of CRC; these can be invasive and non-invasive. Usually, CRC is identified via endoscopic imaging and histopathological examination of removed specimens (biopsies) (10). Colonoscopy is an invasive visual screening tool used to visualize and detect Ps. Other screening tools include fecal occult blood and immunochemical tests, which detect blood in the stool $(8,11,12)$. However, these screening tools have limitations in terms of sensitivity, specificity, cost and degree of 
invasiveness. Therefore, the development of novel diagnostic biomarkers is crucial for early diagnosis of CRC $(13,14)$.

$\mathrm{CRC}$ is considered to be a multifactorial disease that is characterized by a sequence of genetic and epigenetic alterations in the different stages. These alterations are classified into three classes: Chromosomal and microsatellite instability and $\mathrm{CpG}$ island methylation phenotype $(13,15)$. In addition, epigenetic regulators, including long non-coding RNAs and microRNAs (miRNAs or miRs), have been implicated in different types of cancer, including CRC (15). miRNAs, short non-coding RNAs composed of 18-24 nucleotides, are known as gene regulatory molecules for their ability to suppress translational activity by using other miRNAs as cleavage targets, thereby altering the function of protein-coding genes $(13,16)$. miRNAs can be characterized as oncogenic or tumor suppressor miRNAs. Oncogenic miRNAs are upregulated in cancer and mediate downregulation of tumor suppressor genes. By contrast, tumor suppressor miRNAs are downregulated in cancer, which is accompanied by upregulation of oncogenes $(17,18)$. These oncogenes are highly expressed and contribute to cancer development by increasing cellular proliferation and tumor progression (19).

Furthermore, there is an increasing evidence that certain miRNAs are dysregulated in cancer $(17,18)$. Studies have revealed that numerous miRNAs (including miR-21, miR-17-92 cluster, miR-143 and miR-145) are deregulated in patients with CRC and serve an important role in its initiation, development, and progression (20-22). One of the most commonly upregulated miRNAs in CRC is miR-21, which plays an essential role in tumor progression (23).

The role of miR-31, miR-146b, miR-145 and miR-186 have been studied in different types of cancer. Several studies have reported the oncogenic role of miR-31 and miR-146b in different populations and types of cancer, including CRC (24-27). Accordingly, miR-31 has been shown to be upregulated in CRC and is associated with tumor progression, as well as survival rate. However, miR-145 and miR-186 are downregulated in colorectal cancer, which is accompanied by activation of oncogenic mRNAs, such as twist family bHLH transcription factor 1, Fascin Actin-Bundling Protein 1 and Zinc Finger E-Box Binding Homeobox 1 (28-30).

The aim of the present retrospective study was to investigate the expression levels of miRNAs (miR-146b, miR-31, miR-186 and miR-145) in 222 formalin-fixed paraffin-embedded (FFPE) colorectal tissue samples taken from Lebanese patients with different precancerous (P) and cancer stages (Ad and ADC) and to identify miRNAs that may be used for diagnosis, particularly at $\mathrm{P}$ stage.

\section{Materials and methods}

Colon tissue specimens. The present study was approved by the Medical Committee at Bahman Hospital (Beirut, Lebanon; approval no. 27). Retrospective FFPE specimens from 222 patients with $\mathrm{CRC}$ at different stages [P $(\mathrm{n}=68), \operatorname{Ad}(\mathrm{n}=78)$, ADC $(n=76)]$, as well as specimens of normal healthy controls $(\mathrm{N} ; \mathrm{n}=81$ ) were obtained from the Anatomy and Pathology Department, Bahman Hospital, Haret Hreik, Lebanon from patients that underwent colonoscopy and resection between 2011 and 2019, excluding patients with hereditary disease.
Total RNA extraction. Total RNA, including small RNA fraction, was extracted by processing four $20 \mu \mathrm{m}$ thick ribbons from each FFPE tissue sample using a RecoverAll Total Nucleic Acid Isolation kit (Ambion; Thermo Fisher Scientific, Inc.; cat. no. AM1975) according to the manufacturer's instructions. Briefly, deparaffinization of FFPE tissue was performed using xylene at $50^{\circ} \mathrm{C}$ followed by washing with ethanol twice to remove xylene. Proteins were digested by incubating the samples with protease enzyme for $15 \mathrm{~min}$ at $50^{\circ} \mathrm{C}$ and $15 \mathrm{~min}$ at $80^{\circ} \mathrm{C}$. Total RNA was isolated in glass-fiber filter cartridges using an isolation additive mixture and washing with high ethanol-wash buffers. DNA digestion was then performed using DNase and RNA was purified by washing and elution using reagents provided in the kit. RNA concentration and quality were detected using a NanoDrop ND1000 spectrophotometer (Thermo Fisher Scientific, Inc.) by measuring the optical density at 260 and $280 \mathrm{~nm}$, then samples were stored at $-80^{\circ} \mathrm{C}$. Only samples of high quality and integrity (A260/A280 ratio of 1.8-2.1) were used for subsequent experiments.

miRNA reverse transcription $(R T)$ and expression level analysis. A total of $10 \mathrm{ng}$ total RNA was reverse transcribed using TaqMan ${ }^{\circledR}$ MicroRNA RT kit (Applied Biosystems; Thermo Fisher Scientific, Inc.) according to the manufacturer's recommendations. The hsa-miR-146b (cat. no. 001097), hsa-miR-186 (cat. no. 002285), hsa-miR-145 (cat. no. 002278), hsa-miR-31 (cat. no. 002279), small nucleolar RNA RNU48 (cat. no. 001006) primers and probes were used as part of the TaqMan Small RNA Assays ${ }^{\mathrm{TM}}$ kit (Applied Biosystems; Thermo Fisher Scientific, Inc.). RT was performed in a multiplex reaction setup using two miRNA primers with an endogenous control (for example, miR-31 and miR-145 primers were used together with the endogenous control RNU48).

miRNA expression was assessed by RT-quantitative (q)PCR using Bio-Rad CFX96 Real-Time System, C1000 Thermal Cycler (Bio-Rad Laboratories, Inc.). Reactions were performed in duplicate for each miRNA probe using 5.0 TaqMan ${ }^{\circledR}$ Universal Master Mix without Amperase Uracil N-glycosylase (Applied Biosystems; Thermo Fisher Scientific, Inc.; 4324018), $0.520 \mathrm{X}$ microRNA probe, 1.0 diethyl pyrocarbonate-treated water and $3.5 \mu \mathrm{l}$ prepared cDNA. The following probes were used: hsa-miR-31 (cat. no. 002279), hsa-miR-145 (cat. no. 002278), hsa-miR-186 (cat. no. 002285), hsa-miR-146b (cat. no. 001097), RNU48 (cat. no. 001006; all Applied Biosystems). Each plate contained the samples, no template control, no RT control and healthy tissue samples. The thermocycling conditions were $95^{\circ} \mathrm{C}$ for $10 \mathrm{~min}$, followed by 40 cycles of $95^{\circ} \mathrm{C}$ for $15 \mathrm{sec}$ and annealing at $60^{\circ} \mathrm{C}$ for $60 \mathrm{sec}$. Only samples with average miRNA $\mathrm{Cq}<35$ or endogenous control $\mathrm{Cq}$ of $22-29$ were included. The relative expression of target miRNAs at the different stages (P, Ad and ADC) was then normalized to RNU48 and compared with $\mathrm{N}$ using the $2^{-\Delta \Delta \mathrm{Cq}}$ method (31). Normalization of tumor tissues was based on $\mathrm{N}$ present on the RT-qPCR plate to ensure inter-run calibration.

Statistical analysis. Statistical analysis was performed using GraphPad Prism (GraphPad Software, Inc; version 8) and SPSS version 25 software (IBM, Corp.). Patient demographics are presented as mean \pm standard deviation (SD) for continuous variables and as numbers or percentages for categorical variables. 
A

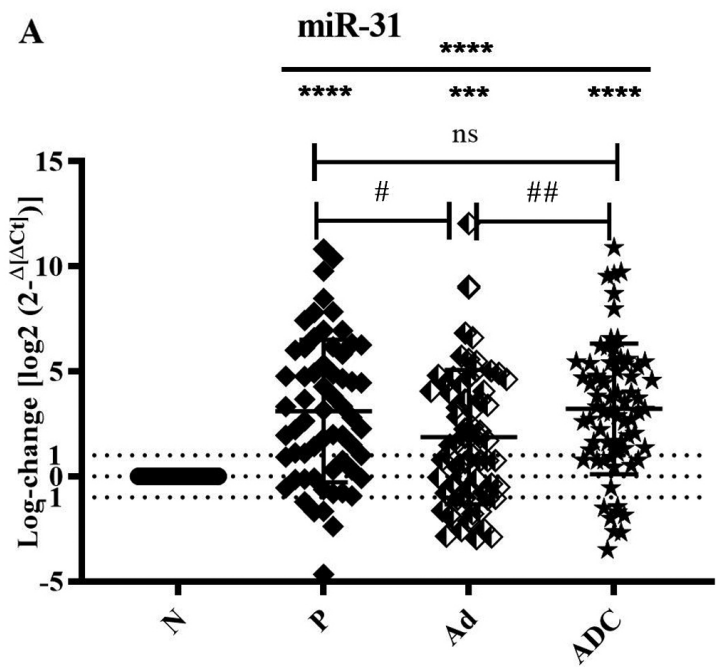

C

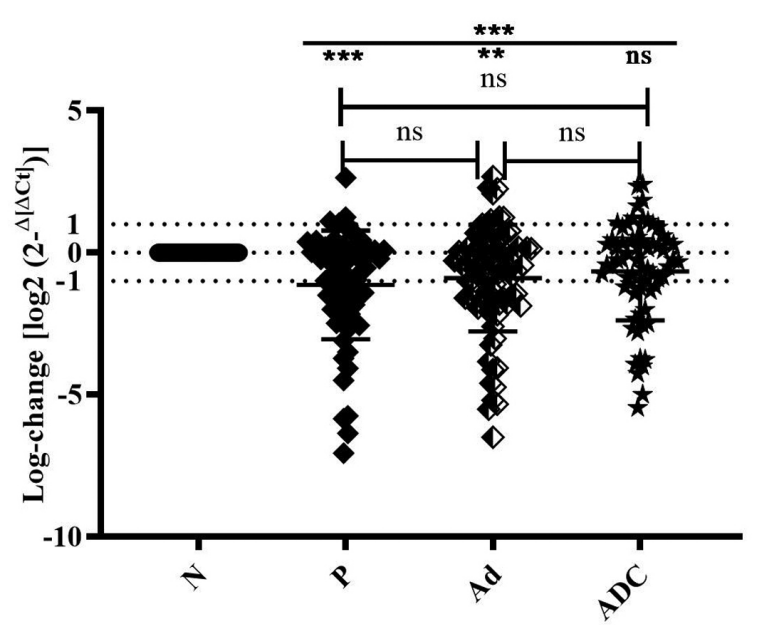

B
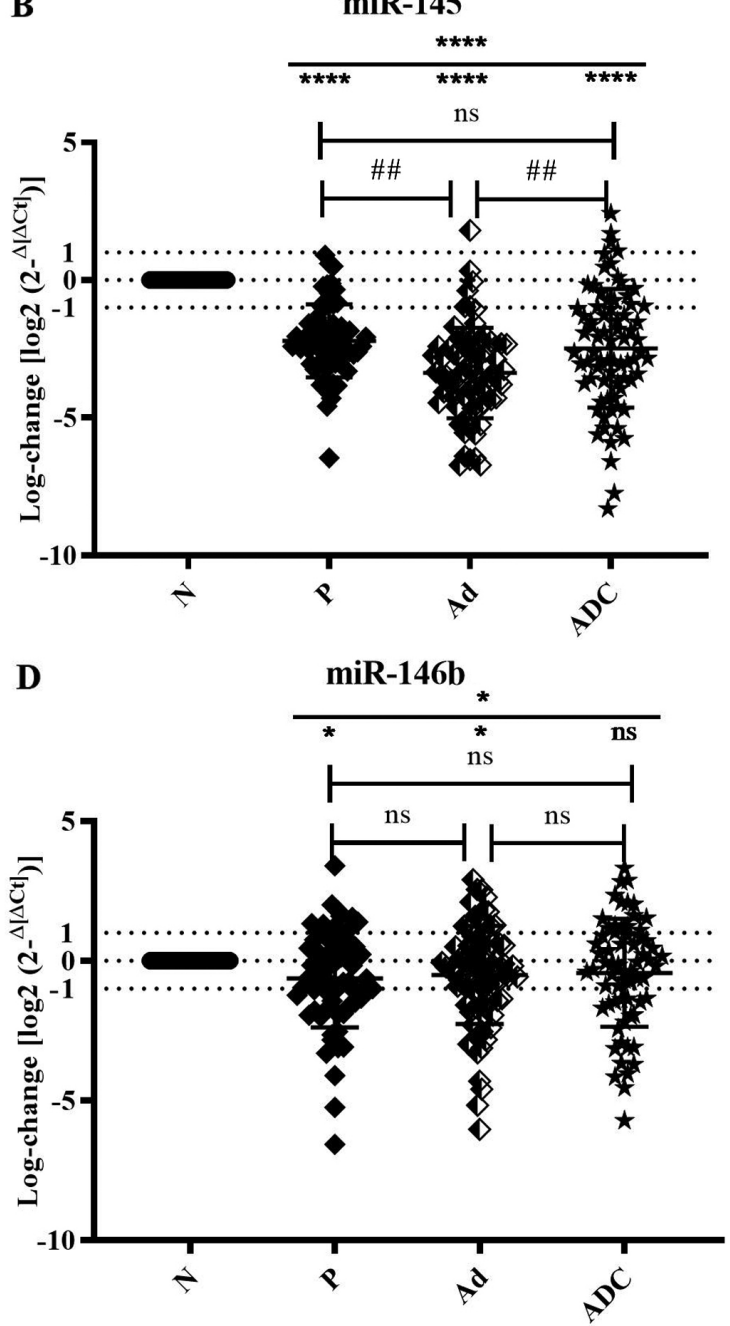

Figure 1.Dysregulation of miR-31, 145, 186 and 146b expression at different stages. Scatter plots show expression profiles of (A) miR-31,(B) miR-145, (C) miR-186 and (D) miR-146b, represented by log-changes at all stages relative to the average $\Delta \mathrm{Cq}$ value of healthy controls (measured by reverse transcription-quantitative PCR with RNU48 as an endogenous control). Data are presented as the mean \pm SEM. Data were analyzed by Kruskal-Wallis $\left({ }^{*} \mathrm{P}<0.05,{ }^{* *} \mathrm{P}<0.01,{ }^{* * * *} \mathrm{P}<0.001\right.$ and $\left.{ }^{* * * *} \mathrm{P}<0.001\right)$ and Dunn's test $\left({ }^{\#} \mathrm{P}<0.05\right.$ and $\left.{ }^{\# \#} \mathrm{P}<0.01\right)$. miR, microRNA; N, normal; $\mathrm{P}$, polyp; Ad, adenoma; ADC, adenocarcinoma; ns, not significant.

Due to the lack of normality, Kruskal-Wallis test was performed to compare expression levels each miRNA at P, Ad, and ADC stages with healthy controls, followed by Dunn's test to perform pairwise comparison. The diagnostic value of miRNAs at $\mathrm{P}$ stage was detected by receiver operating characteristic (ROC) curve analysis using the $\Delta \mathrm{Cq}$ values of the samples and the predicted probability was calculated using binary logistic regression. The ROC curve was plotted to indicate the area under the curve (AUC) and P-value, as well as to calculate the positive predictive and negative predictive values and diagnostic accuracy between $\mathrm{P}$ and $\mathrm{N}$ to determine the diagnostic value of miR-31, miR-145, miR-186 and miR-146b. Youden's index was calculated in addition to the cut-off value, sensitivity and specificity of miRNAs. $\mathrm{P}<0.05$ was considered to indicate a statistically significant difference. Independent set of 20 samples was also used to confirm the diagnostic accuracy of miR-31 and miR-145.

\section{Results}

Clinicopathological characteristics of patients. The features of 303 biopsies are presented in Table I, including 222 patients in the precancerous and cancerous stages with a mean age of $60.15 \pm 15.13$, in addition to $81 \mathrm{~N}$ samples with a mean age of $57.1 \pm 18.66$ years. The male to female ratio was 1.09 for patients and 0.7 for $\mathrm{N}$ samples. $\mathrm{P}$ and Ad samples were all non-malignant (hyperplastic Ps and low-grade Ads). In addition, 93.4\% of ADC samples were grade 2 (moderately differentiated). A total of $0.9 \%$ had Crohn's disease while $0.45 \%$ had a family history of CRC (data not shown).

Overexpression of $m i R-31$ at different stages of $C R C$. The mean expression of miR-31 across all stages was significantly upregulated $(\mathrm{P}<0.0001)$. miR-31 was significantly increased in the $\mathrm{P}, \mathrm{Ad}$ and ADC stages compared with $\mathrm{N}(\mathrm{P}<0.0001$, $\mathrm{P}=0.0007$ and $\mathrm{P}<0.0001$, respectively; Fig. 1A; Table II).

In addition, miR-31 was significantly downregulated in Ad compared with $\mathrm{P}$ stage $(\mathrm{P}=0.0244)$ but significantly upregulated in ADC compared with $\mathrm{Ad}(\mathrm{P}=0.0023)$. However, there was no significant change in its expression at ADC compared with $\mathrm{P}$ stage $(\mathrm{P}=0.4816)$ Therefore, miR-31 expression increased significantly at all stages with respect to healthy controls and at P and ADC stages compared with Ad (Fig. 1A). 
Table I. Clinicopathological characteristics of patients.

\begin{tabular}{|c|c|c|c|c|c|}
\hline Characteristic & Healthy control & Polyp & Adenoma & Adenocarcinoma & $\begin{array}{l}\text { Precancerous and } \\
\text { cancerous stages }\end{array}$ \\
\hline Sample, n (\%) & $81.00(36.40)$ & $68.00(30.70)$ & $78.00(35.10)$ & $76.00(34.38)$ & $222.00(73.26)$ \\
\hline $\begin{array}{l}\text { Age at diagnosis, years } \\
(\text { mean } \pm \text { SD) }\end{array}$ & $57.10 \pm 18.66$ & $58.06 \pm 15.34$ & $58.46 \pm 15.22$ & $63.47 \pm 14.55$ & $60.15 \pm 15.13$ \\
\hline \multicolumn{6}{|l|}{ Sex } \\
\hline Male (\%) & $35.00(43.20)$ & $43.00(63.20)$ & $37.00(47.40)$ & $36.00(47.30)$ & $116.00(52.20)$ \\
\hline Female $(\%)$ & $46.00(56.70)$ & $25.00(36.70)$ & $41.00(52.50)$ & $40.00(52.60)$ & $106.00(47.70)$ \\
\hline Colon margin (\%) & $81(100)$ & & & & \\
\hline Colon $(\%)$ & & $48.00(70.50)$ & $73.00(93.50)$ & $61.00(80.20)$ & $182.00(81.90)$ \\
\hline Right sided colon (\%) & & $13.00(27.00)$ & $11.00(15.00)$ & $14.00(22.90)$ & $38.00(20.80)$ \\
\hline Left sided colon $(\%)$ & & $30.00(62.50)$ & $57.00(78.00)$ & $45.00(73.70)$ & $132.00(72.50)$ \\
\hline Transverse colon (\%) & & $5.00(10.40)$ & $5.00(6.80)$ & $2.00(3.20)$ & $12.00(6.50)$ \\
\hline Rectum (\%) & & $20.00(29.40)$ & $5.00(6.40)$ & $15.00(19.70)$ & $40.00(18.00)$ \\
\hline Tumor grade stage (\%) & & & & $\begin{array}{c}\text { G1, } 3.00(3.90) ; \\
\text { G2, } 71.00(93.40) ; \\
\text { G3/4, } 2.00(2.60)\end{array}$ & \\
\hline
\end{tabular}

G1, well differentiated; G2, moderately differentiated; G3/4, poorly differentiated.

Downregulation of miR-145 in different stages of CRC. Notably, miR-145 was significantly downregulated across $\mathrm{P}$, Ad and ADC stages when compared with $\mathrm{N}(\mathrm{P}<0.0001$; Fig. 1B; Table II).

miR-145 expression was significantly downregulated at Ad compared with $\mathrm{P}(\mathrm{P}=0.0014)$ and at ADC compared with Ad stage $(\mathrm{P}=0.0044)$. However, no significant change in the expression of this miRNA between $\mathrm{P}$ and ADC stage $(\mathrm{P}=0.6184)$ was noted (Fig. 1B).

Dysregulated expression of miR-186 in different stages of CRC. miR-186 was significantly deregulated $(\mathrm{P}=0.0009)$ according to the Kruskal Wallis test. Significant downregulation of miR-186 was observed at $\mathrm{P}$ and $\mathrm{Ad}(\mathrm{P}=0.0006$ and $\mathrm{P}=0.0053$, respectively) compared with $\mathrm{N}$. ADC stage showed a slight but not significant downregulation of miR-186 ( $\mathrm{P}=0.147$; Fig. 1C; Table II).

Evaluation of the expression profile of miR-186 between the different stages showed no significant change between $\mathrm{Ad}$ and $\mathrm{P}(\mathrm{P}=0.4439), \mathrm{ADC}$ and Ad stages $(\mathrm{P}=0.319)$ and $\mathrm{ADC}$ and $\mathrm{P}$ stages $(\mathrm{P}=0.0923$; Fig. 1C).

Expression profile of miR-146b in different stages of CRC. Compared with N, miR-146b demonstrated a significant decrease expression $(\mathrm{P}=0.0241)$. Dunn's test revealed a significant downregulation at $\mathrm{P}(\mathrm{P}=0.026)$ and Ad stages $(\mathrm{P}=0.0263$; Fig. 1D, Table II). No significant change was observed between expression levels of miR-146b in $\mathrm{Ad}$ and $\mathrm{P}(\mathrm{P}=0.8971)$, ADC and $\mathrm{P}(\mathrm{P}=0.3774)$ and $\mathrm{ADC}$ and Ad stages $(\mathrm{P}=0.4279$; Fig. 1D). Therefore, miR-146b expression did not significantly change in the different precancerous and cancerous stages of the disease.

ROC for miR-31, miR-145, miR-186 and miR-146b. The positive and negative predictive value and diagnostic accuracy of miR-31, miR-145, miR-186, and miR-146b were assessed (Table III). miR-31 and miR-145 were found to significantly differentiate between $\mathrm{P}$ and $\mathrm{N}$ (AUC $=0.7771$; 95\% CI, 0.6972-0.8570; $\mathrm{P}<0.0001$ and $\mathrm{AUC}=0.8269 ; 95 \% \mathrm{CI}$, 0.7566-0.8972; $\mathrm{P}<0.0001$, respectively; Fig. 2). At the optimal cut-off values of 2.533 for miR-31 and 2.857 for miR-145, the sensitivity and specificity were 76.67 and 69.74 vs. 80 and $72 \%$, respectively. miR-31 and miR-145 exhibited a diagnostic accuracy of 71.3 and $78.5 \%$ respectively. Moreover, the diagnostic accuracy of miR-31 and miR-145 was 77.4 and 76.7\% respectively, when applied on an independent set of samples (Table SI). On the other hand, miR-186 and miR-146b showed poor discrimination between $\mathrm{P}$ and $\mathrm{N}(\mathrm{AUC}=0.6875$; 95\% CI, 0.5987-0.7763; $\mathrm{P}=0.0002$ and $\mathrm{AUC}=0.6313 ; 95 \% \mathrm{CI}$, $0.5372-0.7253 ; \mathrm{P}=0.0086$, respectively). Therefore, $\mathrm{miR}-31$ and miR-145 can be used as early diagnostic markers to differentiate between $\mathrm{P}$ and $\mathrm{N}$ tissue (Fig. 2).

\section{Discussion}

$\mathrm{CRC}$ is a major worldwide health burden with a high mortality rate (32). Despite the availability of several screening techniques for CRC diagnosis, such as colonoscopy and blood- and stool-based biomarkers, these tests are not ideal and require improvement for effective early diagnosis to increase survival rate $(13,14)$.

Considering the contribution of miRNA in the initiation and progression of cancer, researchers have investigated their role as an early detection biomarker in several types of cancer, including CRC $(20,33,34)$.

miRNA expression varies within populations primarily due to specific genetic variation and single nucleotide polymorphism in mature miRNA $(35,36)$. The present study assessed the expression profile of miRNAs (miR-31, miR-145, 
Table II. Expression levels of miRs-31, -145, -186 and -146b compared with healthy controls.

\begin{tabular}{|c|c|c|c|c|c|}
\hline miRNA & Stage & Number & Mean \pm SD & $95 \% \mathrm{CI}$ & P-value \\
\hline \multirow[t]{3}{*}{ miR-31 } & $\mathrm{P}$ & 61 & $3.1150 \pm 3.3940$ & $2.2460-3.9850$ & $<0.0001$ \\
\hline & Ad & 67 & $1.8750 \pm 3.2030$ & $1.0930-2.6560$ & 0.0007 \\
\hline & $\mathrm{ADC}$ & 70 & $3.2200 \pm 3.1050$ & $2.4800-3.9610$ & $<0.0001$ \\
\hline \multirow[t]{3}{*}{ miR-145 } & $\mathrm{P}$ & 60 & $-2.2090 \pm 1.3250$ & $-2.5510-1.8670$ & $<0.0001$ \\
\hline & Ad & 72 & $-3.3740 \pm 1.6470$ & $-3.7610-2.9870$ & $<0.0001$ \\
\hline & $\mathrm{ADC}$ & 74 & $-2.4780 \pm 2.1590$ & $-2.9780-1.9770$ & $<0.0001$ \\
\hline \multirow[t]{3}{*}{ miR-186 } & $\mathrm{P}$ & 64 & $-1.1270 \pm 1.9140$ & $-1.6050-0.6491$ & 0.0006 \\
\hline & Ad & 78 & $-0.8968 \pm 1.8780$ & $-1.3200-0.4733$ & 0.0053 \\
\hline & $\mathrm{ADC}$ & 65 & $-0.6588 \pm 1.7240$ & $-1.0860-0.2316$ & 0.1470 \\
\hline \multirow[t]{3}{*}{ miR-146b } & $\mathrm{P}$ & 64 & $-0.6320 \pm 1.7520$ & $-1.0700-0.1943$ & 0.0260 \\
\hline & $\mathrm{Ad}$ & 77 & $-0.5011 \pm 1.7560$ & $-0.8997-0.1025$ & 0.0263 \\
\hline & $\mathrm{ADC}$ & 66 & $-0.4283 \pm 1.9330$ & $-0.9035-0.04695$ & 0.2614 \\
\hline
\end{tabular}

P, polyp; Ad, adenoma; ADC, adenocarcinoma; miRNA, microRNA.

A

miR-31

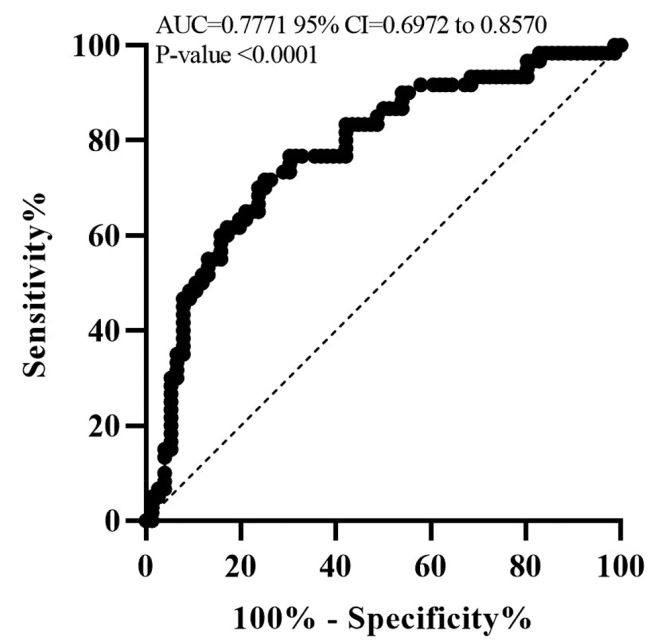

C

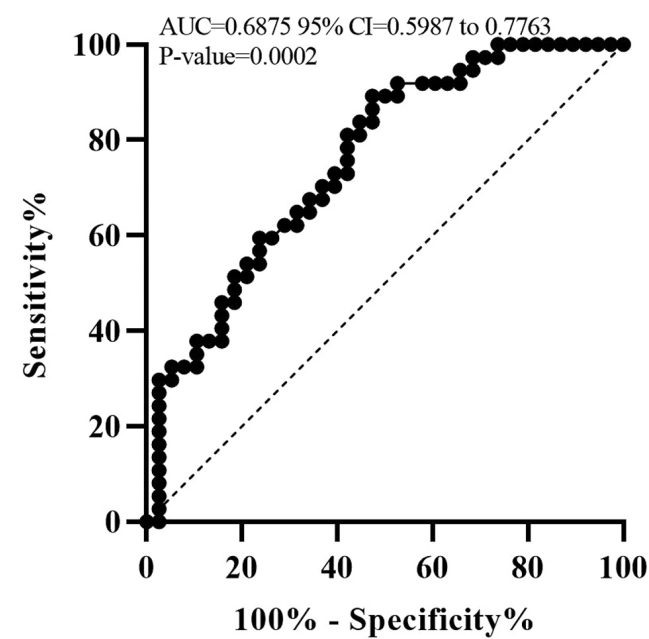

B miR-145

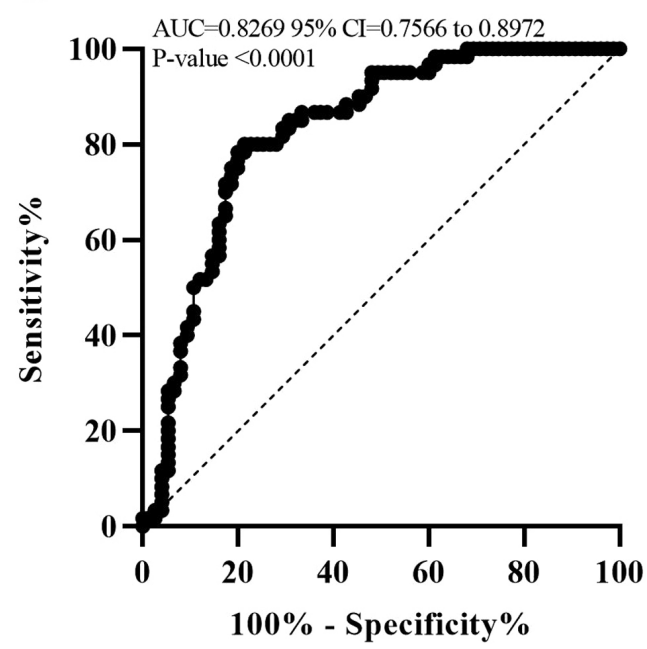

D

miR-146b

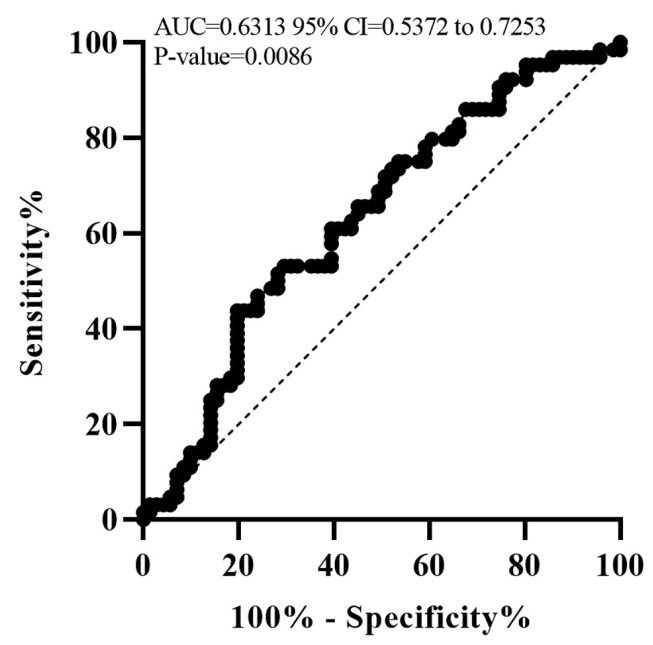

Figure 2. miR-31 and miR-145 show valuable diagnostic potential at P stage. Receiver operator characteristic curve for (A) miR-31, (B) miR-145, (C) miR-186 and (D) miR-146b expression. This graph represents the AUC for miR-31, miR-145, miR-186 and miR-146b to reveal their diagnostic value at $\mathrm{P}$ stage. AUC $<0.5$, no discrimination; $0.5 \leq \mathrm{AUC}<0.7$, poor; $0.7 \leq \mathrm{AUC}<0.8$, acceptable; $0.8 \leq \mathrm{AUC}<0.9$, excellent; AUC $\geq 0.9$, outstanding discrimination. AUC, area under the curve; $\mathrm{P}$, polyp; miR, microRNA. 
Table III. Diagnostic parameters to evaluate the diagnostic potential of miRs at polyp stage.

\begin{tabular}{|c|c|c|c|c|c|c|c|c|c|c|c|}
\hline $\mathrm{miR}$ & AUC & SEM & P-value & $95 \% \mathrm{CI}$ & $\begin{array}{c}\text { Sensitivity, } \\
\%\end{array}$ & $\begin{array}{c}\text { Specificity } \\
\%\end{array}$ & $\begin{array}{l}\text { Cut-off } \\
\text { value }\end{array}$ & $\begin{array}{l}\text { Youden's } \\
\text { index }\end{array}$ & PPV & NPV & $\mathrm{DA}, \%$ \\
\hline $\operatorname{miR}-31$ & 0.7771 & 0.04078 & $<0.0001$ & $0.6972-0.8570$ & 76.67 & 69.74 & 2.533 & 0.4641 & 55.0 & 84.2 & 71.3 \\
\hline miR-145 & 0.8269 & 0.03586 & $<0.0001$ & $0.7566-0.8972$ & 80.00 & 72.00 & 2.857 & 0.5200 & 78.3 & 78.7 & 78.5 \\
\hline miR-186 & 0.6875 & 0.04529 & 0.0002 & $0.5987-0.7763$ & 67.19 & 60.56 & 1.704 & 0.2775 & 48.4 & 78.9 & 64.4 \\
\hline miR-146b & 0.6313 & 0.04799 & 0.0086 & $0.5372-0.7253$ & 60.94 & 60.56 & 1.545 & 0.2150 & 43.8 & 76.1 & 60.7 \\
\hline
\end{tabular}

AUC, area under the curve; PPV, positive predictive value, NPV, negative predictive value; DA, diagnostic accuracy; miRNA, microRNA.

miR-186 and miR-146b) in FFPE tissue of Lebanese patients at different stages (P, Ad and ADC) to identify miRNAs that are aberrantly expressed in CRC samples and highlight miRNAs that may have early diagnostic value. When the different CRC stages were compared with healthy controls, miR-31 was upregulated at all stages $(\mathrm{P}<0.0001)$. By contrast, miR-145, miR-186 and miR-146b were significantly downregulated at all stages $(\mathrm{P}<0.0001,0.0009$ and 0.0241 , respectively). Of these four miRNAs, the present study identified miR-31 and miR-145 as potentially useful diagnostic factors with $\mathrm{AUC}=0.7771$ for miR-31 and 0.8269 for miR-145, and diagnostic accuracy of 71.3 and $78.5 \%$, respectively.

In CRC, dysregulation of miR-31 and miR-145 have been implicated in cell proliferation, invasion and migration in vitro and in tumorigenesis and metastasis in CRC tissue $(37,38)$. miR-31 is reported to be upregulated in CRC tissue suppressing Special AT-rich sequence-binding protein 2 gene and regulating v-Raf murine sarcoma viral oncogene homolog $\mathrm{B}$ activation, serving a role in the signaling pathway downstream of epidermal growth factor receptor $(39,40)$. Furthermore, miR-145 is downregulated in CRC tissue and induces tumorigenesis by acting on its target, Kirsten rat sarcoma viral oncogene homolog (41). Consistent with the present results, the upregulation of miR-31 and downregulation of miR-145 have been reported in CRC tissue in different populations such as the Chinese, Japanese and European populations $(38,42,43)$.

Cui (44) reported that miR-31 upregulation has a high diagnostic value between normal and tumor stages. In addition, Peng et al (45) stated that miR-145 is a potential biomarker for the early diagnosis of CRC. Here, miR-31 and miR-145 significantly differentiated between $\mathrm{P}$ and $\mathrm{N}$ stages $(\mathrm{P}<0.0001$; diagnostic accuracy, 71.3 and $78.5 \%$, respectively). These results indicate that miR-31 and miR-145 detection may be valuable for the early-stage diagnosis of CRC.

miR-186 exhibits contradicting effects in certain types of cancer, including CRC, indicating its role as an onco-miRNA and tumor suppressor miRNA based on its targets (46). Islam et al (47) reported that miR-186 is significantly upregulated in colon tissue and cell lines in a study performed in Australia. Conversely, Li et al (30) reported a significant downregulation of miR-186 in colon tissues in the Chinese population and colon cancer cell lines. Here, miR-186 expression was significantly downregulated at $\mathrm{P}$ stage, accompanied by non-significant downregulation at Ad and ADC stages compared with N. Additionally miR-186 was significantly upregulated at ADC compared with $\mathrm{P}$ and Ad stages. This suggests a role for miR-186 as a potential biomarker at the early stages of multistage CRC carcinogenesis. When the diagnostic role of miR-186 was investigated using ROC analysis, it showed a poor diagnostic role between $\mathrm{P}$ and $\mathrm{N}$ stages with an AUC of 0.6875 and diagnostic accuracy of $64.4 \%$. Hence, miR-186 was shown to be downregulated at $\mathrm{P}$ stage in Lebanese patients but exhibited poor diagnostic value.

miR-146b has been reported to be deregulated in different types of cancer. For example, miR-146b has been shown to be upregulated in papillary thyroid carcinoma and lung and gastric cancer (48-50). However, several studies have reported that miR-146b serves a tumor suppressor function in solid tumors, such as osteosarcoma, pancreatic and breast cancer and glioma (51-54). A study in 2012 reported that miR-146b expression is upregulated from non-neoplastic to dysplastic stage in CRC but downregulated from the dysplasia stage to the cancerous stage in Crohn's disease (27). Zhu et al (26) reported that elevated expression of miR-146b is associated with high prognosis of CRC at the tumor nodule metastasis stage. In the present study, there was no significant change in miR-146b expression at different stages of CRC compared with N. In addition, the ROC curve analysis showed that miR-146b cannot be used as a diagnostic biomarker between $\mathrm{P}$ stage and $\mathrm{N}$. These results are not consistent with previous studies suggesting that miR-146b expression is variable between the Lebanese population and others $(26,27)$. Thus, miR-146b cannot be considered a biomarker to assess the progression of $\mathrm{CRC}$ in the present samples.

Collectively, there is a growing appreciation for the role of miRNA expression in CRC. Among the studied miRNAs, only miR-31 was upregulated in the different stages whereas miR-145, miR-186, and miR-146b were downregulated. In addition, miR-31 and miR-145 can be considered as novel predictive tools for diagnosis of CRC at the early stages of tumorigenesis. Novel miRNA candidates can be added to established screening tools according to the expression levels and hence decrease the burden of this disease and improve survival rate.

\section{Acknowledgements}

Not applicable.

\section{Funding}

The present study was supported by Lebanese University (grant no. 46693). 


\section{Availability of data and materials}

The datasets used and/or analyzed during the current study are available from the corresponding author on reasonable request.

\section{Authors' contributions}

SAS and RAM conceived and designed the study. LA provided FFPE tissue and interpreted the clinicopathological characteristics of patients. SAS, RAM, RAK analyzed and interpreted the data. ZAS and $\mathrm{BH}$ performed statistical analysis. RN conceived the study and revised the manuscript. SAS and RAM wrote the manuscript and confirmed the authenticity of all the raw data. All authors read and approved the final manuscript.

\section{Ethics approval and consent to participate}

The study was approved by the Medical Committee at Bahman Hospital (Beirut, Lebanon; approval no. 27).

\section{Patient consent for publication}

Not applicable.

\section{Competing interests}

The authors declare that they have no competing interests.

\section{References}

1. Ferlay J, Soerjomataram I, Dikshit R, Eser S, Mathers C, Rebelo M, Parkin DM, Forman D and Bray F: Cancer incidence and mortality worldwide: Sources, methods and major patterns in GLOBOCAN 2012. Int J Cancer 136: E359-E386, 2015.

2. Zhang J, Raju GS, Chang DW, Lin S-H, Chen Z and Wu X: Global and targeted circulating microRNA profiling of colorectal adenoma and colorectal cancer. Cancer 124: 785-796, 2018.

3. Rawla P, Sunkara T and Barsouk A: Epidemiology of colorectal cancer: Incidence, mortality, survival, and risk factors. Prz Gastroenterol 14: 89-103, 2019.

4. International Agency for Research on Cancer: Estimated crude incidence and mortality rates in 2020 , worldwide, both sexes, all ages. IARC, Lyon, 2020.

5. Sung JJY, Ng SC, Chan FKL, Chiu HM, Kim HS, Matsuda T, $\mathrm{Ng}$ SS, Lau JY, Zheng S, Adler S, et al; Asia Pacific Working Group: An updated Asia Pacific Consensus Recommendations on colorectal cancer screening. Gut 64: 121-132, 2015.

6. Shamseddine A: Cancer trends in Lebanon and projections to 2020. Human \& Health, 2015. https://www.syndicateofhospitals. org.lb/Content/uploads/SyndicateMagazinePdfs/8217_8-11.pdf

7. Nagy ZB, Wichmann B, Kalmár A, Galamb O, Barták BK Spisák S, Tulassay Z and Molnár B: Colorectal adenoma and carcinoma specific miRNA profiles in biopsy and their expression in plasma specimens. Clin Epigenetics 9: 22, 2017.

8. American Cancer Society: Colorectal Cancer Facts and Figures 2020-2022. American Cancer Society, Atlanta, GA, 2020.

9. Cole SR, Tucker GR, Osborne JM, Byrne SE, Bampton PA, Fraser RJ and Young GP: Shift to earlier stage at diagnosis as a consequence of the National Bowel Cancer Screening Program. Med J Aust 198: 327-330, 2013.

10. Ni Y, Xie G and Jia W: Metabonomics of human colorectal cancer: New approaches for early diagnosis and biomarker discovery. J Proteome Res 13: 3857-3870, 2014.

11. Knudsen AB, Zauber AG, Rutter CM, Naber SK, Doria-Rose VP, Pabiniak C, Johanson C, Fischer SE, Lansdorp-Vogelaar I and Kuntz KM: Estimation of benefits, burden, and harms of colorectal cancer screening strategies: Modeling Study for the US Preventive Services Task Force. JAMA 315: 2595-2609, 2016
12. Gellad ZF, Stechuchak KM, Fisher DA, Olsen MK, McDuffie JR, Østbye T and Yancy WS: Am J Gastroenterol 106: 1125-1134, 2011.

13. Brînzan C, Aşchie M, Cozaru G, Dumitru E and Mitroi A: The diagnostic value of miR-92a, -143 , and -145 expression levels in patients with colorectal adenocarcinoma from Romania. Medicine (Baltimore) 99: e21895, 2020.

14. Al-Sheikh YA, Ghneim HK, Softa KI, Al-Jobran AA, Al-Obeed O, Mohamed MA, Abdulla M and Aboul-Soud MA: Expression profiling of selected microRNA signatures in plasma and tissues of Saudi colorectal cancer patients by qPCR. Oncol Lett 11: 1406-1412, 2016.

15. Jung G, Hernández-Illán E, Moreira L, Balaguer F and Goel A: Epigenetics of colorectal cancer: Biomarker and therapeutic potential. Nat Rev Gastroenterol Hepatol 17: 111-130, 2020.

16. Xiao Z, Chen S, Feng S, Li Y, Zou J, Ling H, Zeng Y and Zeng X: Function and mechanisms of microRNA-20a in colorectal cancer. Exp Ther Med 19: 1605-1616, 2020.

17. Forterre A, Komuro H, Aminova S and Harada M: A comprehensive review of cancer MicroRNA therapeutic delivery strategies. Cancers (Basel) 12: 1852, 2020.

18. Gasparello J, Papi C, Allegretti M, Giordani E, Carboni F, Zazza S, Pescarmona E, Romania P, Giacomini P, Scapoli C, et al: A distinctive microRNA (miRNA) signature in the blood of colorectal cancer (CRC) patients at surgery. Cancers (Basel) 12: $12,2020$.

19. Vishnoi K, Viswakarma N, Rana A and Rana B: Transcription factors in cancer development and therapy. Cancers (Basel) 12: E2296, 2020.

20. Schetter AJ, Okayama $\mathrm{H}$ and Harris CC: The role of microRNAs in colorectal cancer. Cancer J 18: 244-252, 2012.

21. Meng W-J, Yang L, Ma Q, Zhang H, Adell G, Arbman G, Wang ZQ, Li Y, Zhou ZG and Sun XF: MicroRNA expression profile reveals miR-17-92 and miR-143-145 cluster in synchronous colorectal cancer. Medicine (Baltimore) 94: e1297, 2015.

22. Schee K, Boye K, Abrahamsen TW, Fodstad $\varnothing$ and Flatmark K: Clinical relevance of microRNA miR-21, miR-31, miR-92a, miR-101, miR-106a and miR-145 in colorectal cancer. BMC Cancer 12: 505, 2012.

23. Saberinia A, Alinezhad A, Jafari F, Soltany S and Akhavan Sigari R: Oncogenic miRNAs and target therapies in colorectal cancer. Clin Chim Acta 508: 77-91, 2020.

24. Eslamizadeh S, Heidari M, Agah S, Faghihloo E, Ghazi H, Mirzaei A and Akbari A: The role of MicroRNA signature as diagnostic biomarkers in different clinical stages of colorectal cancer. Cell J 20: 220-230, 2018.

25. Slattery ML, Pellatt AJ, Lee FY, Herrick JS, Samowitz WS, Stevens JR, Wolff RK and Mullany LE: Infrequently expressed miRNAs influence survival after diagnosis with colorectal cancer. Oncotarget 8: 83845-83859, 2017.

26. Zhu Y, Wu G, Yan W, Zhan H and Sun P: miR-146b-5p regulates cell growth, invasion, and metabolism by targeting PDHB in colorectal cancer. Am J Cancer Res 7: 1136-1150, 2017.

27. Kanaan Z, Rai SN, Eichenberger MR, Barnes C, Dworkin AM, Weller C, Cohen E, Roberts H, Keskey B, Petras RE, et al: Differential microRNA expression tracks neoplastic progression in inflammatory bowel disease-associated colorectal cancer. Hum Mutat 33: 551-560, 2012.

28. Shen X, Jiang H, Chen Z, Lu B, Zhu Y, Mao J, Chai K and Chen W: MicroRNA-145 inhibits cell migration and invasion in colorectal cancer by targeting TWIST. OncoTargets Ther 12: 10799-10809, 2019.

29. Feng Y, Zhu J, Ou C, Deng Z, Chen M, Huang W and Li L: MicroRNA-145 inhibits tumour growth and metastasis in colorectal cancer by targeting fascin-1. Br J Cancer 110: 2300-2309, 2014.

30. Li J, Xia L, Zhou Z, Zuo Z, Xu C, Song H and Cai J: MiR-186-5p upregulation inhibits proliferation, metastasis and epithelial-to-mesenchymal transition of colorectal cancer cell by targeting ZEB1. Arch Biochem Biophys 640: 53-60, 2018.

31. Livak KJ and Schmittgen TD: Analysis of relative gene expression data using real-time quantitative PCR and the 2(- $\Delta \Delta \mathrm{C}(\mathrm{T}))$ Method. Methods 25: 402-408, 2001.

32. To KK, Tong CW, Wu M and Cho WC: MicroRNAs in the prognosis and therapy of colorectal cancer: From bench to bedside. World J Gastroenterol 24: 2949-2973, 2018.

33. Lan H, Lu H, Wang $X$ and Jin H: MicroRNAs as potential biomarkers in cancer: Opportunities and challenges. BioMed Res Int 2015: 125094, 2015.

34. Hrašovec $\mathrm{S}$ and Glavač D: MicroRNAs as novel biomarkers in colorectal cancer. Front Genet 3: 180, 2012. 
35. Jarry J, Schadendorf D, Greenwood C, Spatz A and van Kempen LC: The validity of circulating microRNAs in oncology: Five years of challenges and contradictions. Mol Oncol 8: 819-829, 2014.

36. Rawlings-Goss RA, Campbell MC and Tishkoff SA: Global population-specific variation in miRNA associated with cancer risk and clinical biomarkers. BMC Med Genomics 7: 53, 2014.

37. Yu T, Ma P, Wu D, Shu Y and Gao W: Functions and mechanisms of microRNA-31 in human cancers. Biomed Pharmacother 108: $1162-1169,2018$

38. Wang D, Liu Q, Ren Y, Zhang Y, Wang X and Liu B: Association analysis of miRNA-related genetic polymorphisms in miR-143/145 and KRAS with colorectal cancer susceptibility and survival. Biosci Rep 41: 41, 2021.

39. Mi B, Li Q, Li T, Liu G and Sai J: High miR-31-5p expression promotes colon adenocarcinoma progression by targeting TNS1. Aging (Albany NY) 12: 7480-7490, 2020.

40. Igarashi $H$, Kurihara $H$, Mitsuhashi K, Ito M, Okuda $H$, Kanno $S$, Naito T, Yoshii S, Takahashi H, Kusumi T, et al: Association of MicroRNA-31-5p with clinical efficacy of anti-EGFR therapy in patients with metastatic colorectal cancer. Ann Surg Oncol 22: 2640-2648, 2015.

41. Michael MZ, O' Connor SM, van Holst Pellekaan NG, Young GP and James RJ: Reduced accumulation of specific microRNAs in colorectal neoplasia. Mol Cancer Res 1: 882-891, 2003

42. Toiyama Y, Takahashi M, Hur K, Nagasaka T, Tanaka K, Inoue Y, Kusunoki M, Boland CR and Goel A: Serum miR-21 as a diagnostic and prognostic biomarker in colorectal cancer. J Natl Cancer Inst 105: 849-859, 2013.

43. Slaby O, Svoboda M, Fabian P, Smerdova T, Knoflickova D, Bednarikova M, Nenutil R and Vyzula R: Altered expression of miR-21, miR-31, miR-143 and miR-145 is related to clinicopathologic features of colorectal cancer. Oncology 72: 397-402, 2007.

44. Cui Q: Significance of miR-27a and miR-31 in early diagnosis and prognosis of colorectal cancer. Oncol Lett 18: 3092-3096, 2019.

45. Peng J, Xie Z, Cheng L, Zhang Y, Chen J, Yu H, Li Z and Kang H: Paired design study by real-time PCR: miR-378* and miR-145 are potent early diagnostic biomarkers of human colorectal cancer. BMC Cancer 15: 158, 2015.
46. Xiang Y, Tian Q, Guan L and Niu S-S: The dual role of miR-186 in cancers: Oncomir battling with tumor suppressor miRNA. Front Oncol 10: 233, 2020.

47. Islam F, Gopalan V, Vider J, Wahab R, Ebrahimi F, Lu CT, Kasem K and Lam AKY: MicroRNA-186-5p overexpression modulates colon cancer growth by repressing the expression of the FAM134B tumour inhibitor. Exp Cell Res 357: 260-270, 2017.

48. Geraldo MV,Fuziwara CS, Friguglieti CU, Costa RB, Kulcsar MA, Yamashita AS and Kimura ET: MicroRNAs miR-146-5p and let-7f as prognostic tools for aggressive papillary thyroid carcinoma: A case report. Arq Bras Endocrinol Metabol 56: 552-557, 2012.

49. Patnaik SK,KannistoE,Mallick Rand Yendamuri S: Overexpression of the lung cancer-prognostic miR-146b microRNAs has a minimal and negative effect on the malignant phenotype of A549 lung cancer cells. PLoS One 6: e22379, 2011.

50. Yoon SO, Kim EK, Lee M, Jung WY, Lee H, Kang Y, Jang YJ, Hong SW, Choi SH and Yang WI: NOVA1 inhibition by miR-146b-5p in the remnant tissue microenvironment defines occult residual disease after gastric cancer removal. Oncotarget 7 : 2475-2495, 2016

51. Al-Khalaf HH and Aboussekhra A: MicroRNA-141 and microRNA-146b-5p inhibit the prometastatic mesenchymal characteristics through the RNA-binding protein AUF1 targeting the transcription factor ZEB1 and the protein kinase AKT. J Biol Chem 289: 31433-31447, 2014.

52. Lin F, Wang X, Jie Z, Hong X, Li X, Wang M and Yu Y: Inhibitory effects of miR-146b-5p on cell migration and invasion of pancreatic cancer by targeting MMP16. J Huazhong Univ Sci Technolog Med Sci 31: 509-514, 2011

53. Hurst DR, Edmonds MD, Scott GK, Benz CC, Vaidya KS and Welch DR: Breast cancer metastasis suppressor 1 up-regulates miR-146, which suppresses breast cancer metastasis. Cancer Res 69: 1279-1283, 2009.

54. Katakowski M, Zheng X, Jiang F, Rogers T, Szalad A and Chopp M: MiR-146b-5p suppresses EGFR expression and reduces in vitro migration and invasion of glioma. Cancer Invest 28: 1024-1030, 2010. 